\title{
Tradition chantée de Bretagne. Les sources du Barzaz
} Breiz aujourd'hui

Yves Defrance

\section{OpenEdition}

1 Journals

Édition électronique

URL : http://journals.openedition.org/ethnomusicologie/1531

ISSN : 2235-7688

Éditeur

ADEM - Ateliers d'ethnomusicologie

Édition imprimée

Date de publication : 31 octobre 1993

Pagination : 261-263

ISBN : 2-8257-0485-7

ISSN : 1662-372X

\section{Référence électronique}

Yves Defrance, «Tradition chantée de Bretagne. Les sources du Barzaz Breiz aujourd'hui », Cahiers

d'ethnomusicologie [En ligne], 6 | 1993, mis en ligne le 02 janvier 2012, consulté le 23 avril 2019. URL : http://journals.openedition.org/ethnomusicologie/1531

Ce document a été généré automatiquement le 23 avril 2019.

Article L.111-1 du Code de la propriété intellectuelle. 


\title{
Tradition chantée de Bretagne. Les sources du Barzaz Breiz aujourd'hui
}

\author{
Yves Defrance
}

\section{RÉFÉRENCE}

Tradition chantée de Bretagne. Les sources du Barzaz Breiz aujourd'hui. 1 CD, collection

Chanteurs et musiciens traditionnels, nouvelle série, vol. I. ArMen-Dastum. 79'.

1 Stupéfiant que ce florilège d'enregistrements réalisés ces trente dernières années en Basse-Bretagne! Vingt pièces, véritables témoins des premières collectes de La Villemarqué, sont ici interprétées par des chanteurs de vingt à quatre-vingts ans. Mises à part deux pièces, toutes ces poésies chantées sont venues jusqu'à nous par une transmission orale ininterrompue, et c'est bien là le plus étonnant. Aux côtés des rouleaux de cire réalisés par François Vallée en 1900 auprès de la grande chanteuse Marc'harid Fulup, née en 1837, figurent des interprètes de tout âge mais de qualité indiscutable. On y retrouve Catherine Guern, immortalisée dans les années 1960 par la maison de disques Mouez-Breiz, les trois sœurs Maïvon, Eugénie et Tasie Goadec, popularisées par leur passage en 1974 sur la scène du music-hall parisien «Bobino ", Marie-Josèphe Bertrand, Mari Harnay, consacrée par OCORA-Radio France, Manu Kerjean, le maître d'Erik Marchand, le désormais très célèbre Yann-Fanch Kemener, mais encore une demi-douzaine de chanteuses et chanteurs de grand talent, parmi lesquels on retiendra la jeune génération des Annie Ebrel, Claude Lintanf et Ifig Troadeg (nés respectivement en 1969, 1962 et 1953). La confrontation des générations parle d'ellemême et c'est une très forte impression de continuité qui se dégage à l'écoute de ces 17 gwerziou, de ces deux chants à danser interprétés en kan ha diskan et d'un récit légendaire conté. Comme le précisent Donatien Laurent et Patrick Malrieu, concepteurs de ce superbe disque, l'objet « est de montrer comment, cent cinquante ans après la parution du Barzaz-Breiz, la tradition poétique chantée de langue bretonne - celle-là même que La Villemarqué avait interrogée et si brillamment mise à contribution - s'est maintenue 
imperturbablement - quoiqu'en déclinant très fortement - à l'ombre de son recueil prestigieux ».

2 Un livret fort d'une centaine de pages accompagne le disque. Sa lecture nous renseigne sur les conditions des enregistrements, les lieux des collectes, réalisées par une quinzaine d'enquêteurs, qui nous donnent de surcroît une notice biographique pour chaque chanteur. Donatien Laurent, Patrick Malrieu et Michel Colleu traitent dans une première partie des grands interprètes de gwerziou, de la tradition orale en 1989, du Barzaz-Breiz lui-même et d'une rétrospective de 150 ans de collectes en Bretagne. La seconde partie, la plus importante, donne l'intégralité des textes bretons transcrits dans le dialecte d'origine et traduits en français. Un commentaire succinct mais précis précède chaque chant pour lequel d'utiles références bibliographiques et discographiques sont données. Quelques illustrations complètent ce riche livret que le lecteur peut aisément parcourir tout en écoutant les admirables voix au timbre naturel et au style si pénétrant. Une belle occasion pour découvrir le breton, dernière langue celtique vivante du continent.

Réjouissons-nous de cette heureuse initiative qui témoigne d'un réel regain pour la tradition de gwerziou, chantées ici intégralement a cappella. Après l'euphorie du revival des années 1970 où les groupes, à dominante instrumentale, se lançaient dans des explorations sonores audacieuses et plus ou moins réussies, on peut se féliciter d'assister à un retour vers un certain dépouillement, un désir d'authenticité, voire de pureté, dans l'interprétation d'une tradition musicale toujours vivante. Dans le sillage de Yann-Fanch Kemener qui réalisa ces quinze dernières années pas moins de quatre albums solo de "Chants profonds de Bretagne » et deux albums accompagnés (Monodies traditionnelles de Bretagne et Barzaz), il faudrait citer Erik Marchand (An hentoù treuz) ou Andrea Ar Gouilh ( Barzaz Breiz). Ainsi, beaucoup de chants que La Villemarqué avait entendus et notés sur son carnet ont poursuivi leur cheminement souterrain dans les mémoires jusqu'à ce qu'aujourd'hui on se préoccupe de les enregistrer. "Certaines de ces versions contemporaines sont même parfois plus complètes et plus cohérentes que celles que La Villemarqué a transcrites il y a plus d'un siècle et demi ", soulignent les auteurs de notre livret. Et d'ajouter avec perspicacité : «On peut d'ailleurs se demander dans quelle mesure le Barzaz Breiz, en valorisant ainsi auprès du public lettré la chanson populaire bretonne, n'a pas contribué indirectement à en prolonger l'existence... ». 